\title{
Peripheral nerve concentrations of glucose, fructose, sorbitol and myoinositol in diabetic and non-diabetic patients
}

\author{
P. J.Hale ${ }^{1}$, M. Nattrass ${ }^{1}$, S. H. Silverman ${ }^{1}$, C. Sennit ${ }^{2}$, C. M.Perkins ${ }^{2}$, A. Uden ${ }^{3}$ and G. Sundkvist ${ }^{4}$ \\ ${ }^{1}$ Diabetic Clinic, General Hospital, Birmingham and ${ }^{2}$ ICI Pharmaceuticals, Macclesfield, Cheshire, UK; ${ }^{3}$ Departments of Orthopaedics and \\ ${ }^{4}$ Medicine, University of Lund, Malmo General Hospital, Malmo, Sweden
}

\begin{abstract}
Summary. Glucose, fructose, sorbitol and myoinositol concentrations were measured in biopsies of peripheral nerve obtained at above-knee or below-knee amputation. In diabetic patients nerve glucose (median [range]) $(5.09$ [1.62-12.82] vs $3.12[1.81-4.01]) p<0.001$, fructose $(0.245[0.060-1.280]$ vs $0.150[0.053-0.385]) p<0.05$, and sorbitol $(0.028[0.012-0.496]$ vs $0.016[0.007-0.059] p<0.02, \mu \mathrm{mol} / \mathrm{g}$ wet weight) were sig-
\end{abstract}

nificantly higher than in non-diabetic patients. No significant difference was found in myoinositol concentration (1.95 [1.00-3.55] vs 2.09 [1.27-5.40] $\mu \mathrm{mol} / \mathrm{g}$ wet weight). Concentrations differed markedly from previously reported values in human nerve obtained at post-mortem.

Key words: Nerve glucose, fructose, sorbitol, myoinositol.
Elevation of nerve concentrations of sorbitol and fructose and reduction of nerve concentration of myoinositol are well recognised features of experimentally induced diabetes mellitus in animals. They are thought to be important in the neuropathy associated with diabetes mellitus in both animals and man [1-7].

While sorbitol, fructose, glucose and myoinositol concentrations have been measured in sciatic nerves obtained at post-mortem in diabetic and non-diabetic patients [8], in vivo measurements have been confined to sural nerve biopsies [9]. In order to obtain a better estimate in vivo in man, we have measured concentrations in proximal nerve biopsies taken at above knee (sciatic nerve) and below knee (common peroneal nerve) amputations performed for either neuropathic sepsis or peripheral vascular disease in diabetic and non-diabetic patients.

\section{Subjects and methods}

Nerve biopsies were obtained from 16 non-diabetic patients (11 men) with a mean age of 71 years (range 31-88 years) and from 21 diabetic patients (14 men) (Table 1). The mean age of the diabetic patients was 67 years (range 49-81 years) and the time since diagnosis of diabetes ranged from 1 to 33 years (mean 15 years). One patient was treated by diet alone, 7 with oral hypoglycaemic agents and 13 with insulin.

In the non-diabetic patients amputation was performed because of severe peripheral vascular disease, 13 were below-knee amputations and 3 above-knee.
In the diabetic group 12 amputations were for peripheral vascular disease, ( 9 below-knee) and 9 amputations for neuropathic sepsis (all below-knee). In all patients the amputation wound healed satisfactorily.

Peri-operative treatment of diabetes was with intravenous glucose $(5 \%)$ and insulin infusion (14 patients), glucose (5\%) and subcutaneous insulin $(n=2)$, or temporary withdrawal of oral hypoglycaemic agents $(n=5)$.

At operation $2-3 \mathrm{~cm}$ length of nerve was taken from the proximal amputation stump, fat and connective tissue removed and the tissue wrapped in a square of tin foil. The sample was then deep frozen at $-70^{\circ} \mathrm{C}$ within 2 min of biopsy. Samples were stored at $-70^{\circ} \mathrm{C}$ until sugar extraction and analysis was performed.

Sugars were extracted from tissue by first homogenising in an equivalent of $13 \mathrm{ml}$ of an aqueous solution of $\alpha$ methyl-D-mannoside $(23 \mu \mathrm{g} / \mathrm{ml})$ per gram wet weight of nerve tissue, followed by boiling for $20 \mathrm{~min}$ [10-12]. Protein was removed by precipitation with barium hydroxide and zinc sulphate [13] and the remaining solution lyophilised. Trimethylsilyl ethers of the sugars in this sample were made using a pyridine/hexamethyldisilazine/trimethylchlorsilane mixture (10:2:1) (Pierce Chemical Company, Rockford, Ill, USA) [14]. The silylated derivatives were then partitioned between water and cyclohexane and the organic phase chromatographed using a Hewlett Packard HP 5890 GLC fitted with cross-linked methyl silicone $25-\mathrm{m}$ capillary column.

Using this method the completeness of extraction from nerve tissue is $98.2 \%$. No significant differences have been found in measurement of levels of glucose, fructose, sorbitol and myoinositol when extraction has been homogenisation in an aqueous media, treatment with perchloric acid solutions, extraction from powdered tissues, or boiling in water. Using boiling as the method of extraction gives a percentage recovery of added standard sugars of $104 \%$. No significant differences have been detected in sugar levels extracted by boiling where enzymes are heat-denatured, and in extracts where protein was precipitated using Somogyi zinc and barium reagents but deproteinising samples after boiling gave cleaner GLC traces without contaminating proteins. 
Table 1. Details of diabetic and non-diabetic patients studied

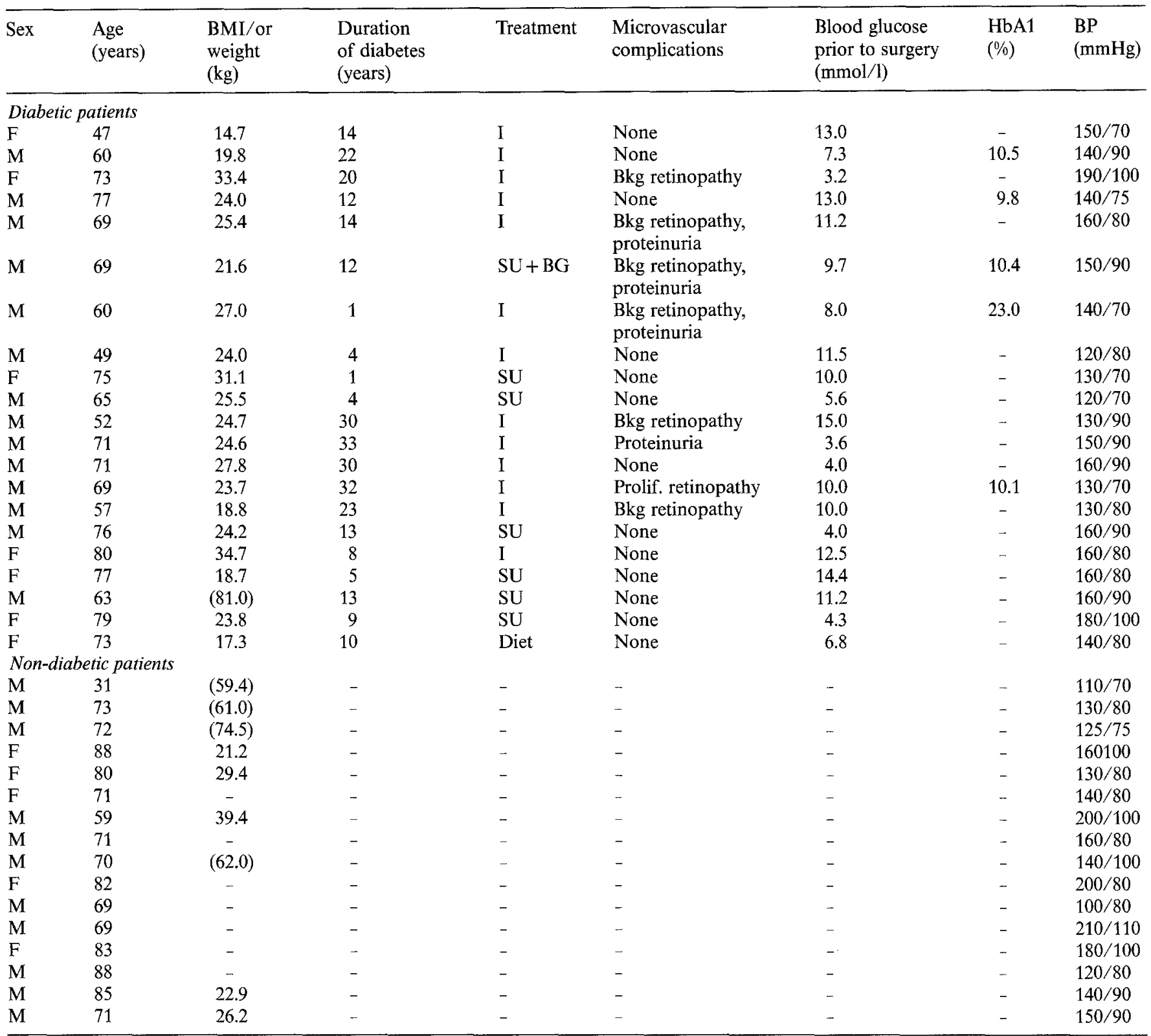

I, insulin; SU, sulphonylurea; BG, biguanide treatment

\section{Statistical analysis}

The Mann-Whitney U test was used to determine statistical differences between the two groups, corrected for ties in the data where appropriate [15].

\section{Results}

Individual results for glucose, sorbitol, fructose and myoinositol are shown in Figures 1 and 2.

Nerve concentrations of glucose $(p<0.001)$, sorbitol $(p<0.02)$, and fructose $(p<0.05)$ were significantly higher in diabetic than in non-diabetic patients, but no significant difference was observed for myoinositol.

There were no significant differences in sugars and myoinositol concentrations between sciatic $(n=6)$ and common peroneal $(n=31)$ nerve biopsies. In addition, no significant differences were found between the diabetic patients who did and did not receive intravenous dextrose and insulin over the period of surgery.

No significant correlation was found between glucose and sorbitol for either the non-diabetic patients $(r=-0.00)$ or the diabetic patients $(r=-0.05)$. There were no significant correlations between any of the other sugars nor between glucose, sorbitol or fructose and myoinositol.

\section{Discussion}

Elevated nerve sorbitol and fructose concentrations are a feature of experimental diabetes [1-7]. Similar increases were found in sciatic nerve obtained at postmortem from diabetic patients [8]. Our results confirm 

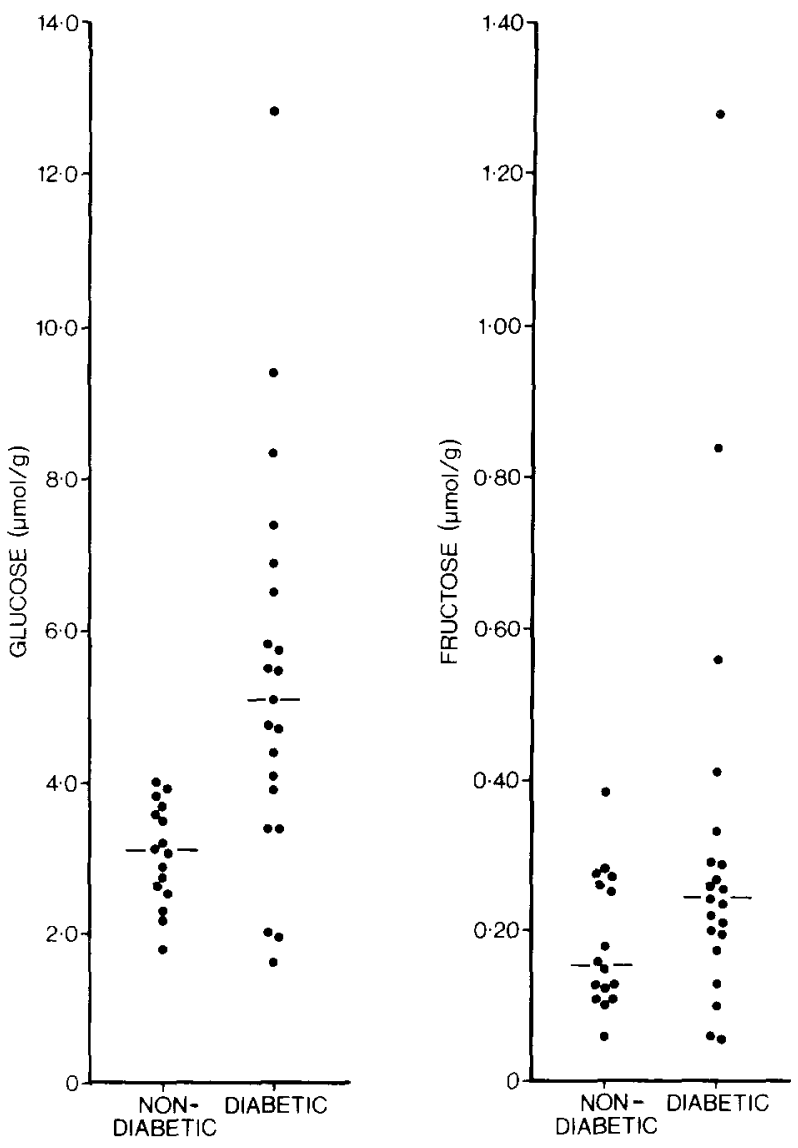

Fig. 1. Concentrations of glucose and fructose $(\mu \mathrm{mol} / \mathrm{g}$ wet weight) in nerve biopsies from 16 non-diabetic and 21 diabetic patients. Individual results and median value are presented
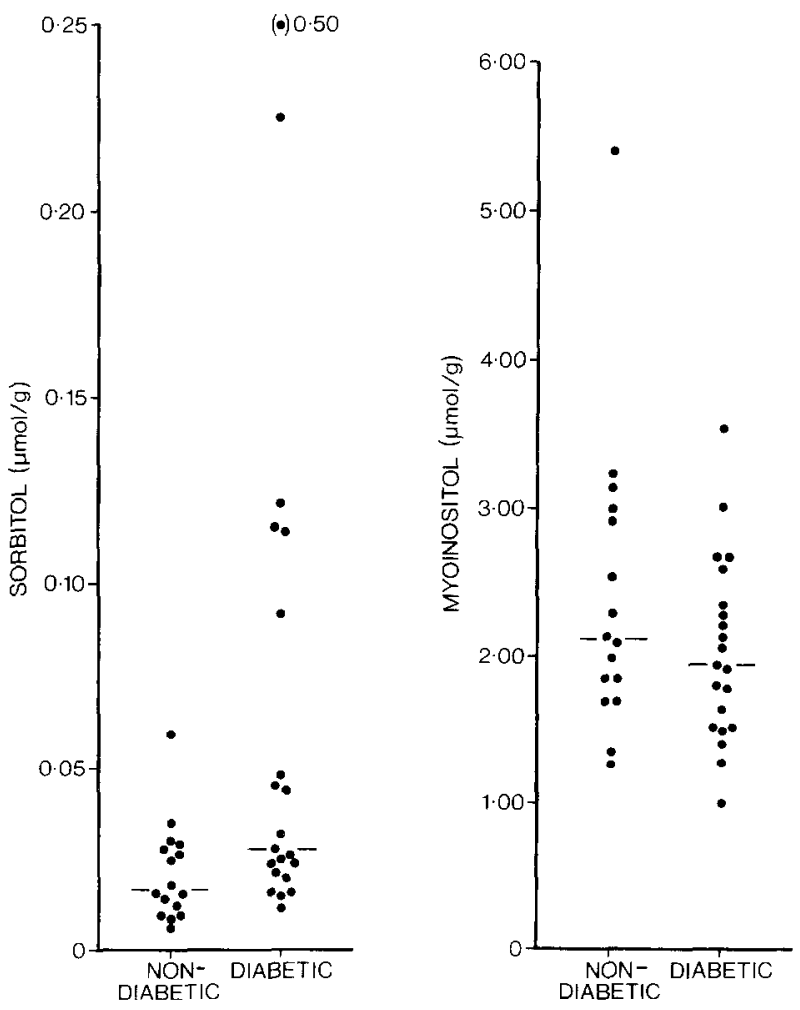

Fig. 2. Concentrations of sorbitol and myoinositol $(\mu \mathrm{mol} / \mathrm{g}$ wet weight) in nerve biopsies from 16 non-diabetic and 21 diabetic patients. Individual results and median value are presented these findings compared with non-diabetic patients, but there are marked differences between the results in our operative biopsies compared with post-mortem specimens. Mayhew et al. [8] reported sorbitol concentrations of $0.09 \pm 0.10 \mu \mathrm{mol} / \mathrm{g}$ (mean $\pm \mathrm{SD}$ ) in non-diabetic and $0.39 \pm 0.49 \mu \mathrm{mol} / \mathrm{g}$ in diabetic patients. These mean values are approximately 5-fold and 14-fold higher than our median values respectively. Similarly nerve fructose concentrations from diabetic patients were much higher than in the present study. The reason for this discrepancy between post-mortem and operative biopsy results probably relates to the considerably lower nerve glucose concentrations in post-mortem nerves. Mayhew et al. [8] reported mean values of $0.46 \mu \mathrm{mol} / \mathrm{g}$ for non-diabetic and $1.61 \mu \mathrm{mol} / \mathrm{g}$ for diabetic patients compared with our results of 3.12 and $5.09 \mu \mathrm{mol} / \mathrm{g}$, respectively, implying post-mortem glucose metabolism to sorbitol and fructose.

In the study of Dyck et al. [9] on in vivo sural nerve biopsy, 9 of the 20 diabetic patients were untreated, and no information is given on sural nerve glucose concentration. No significant differences were observed for nerve sorbitol or fructose between the diabetic and non-diabetic groups. Although values for both were higher than found in the present study, Dyck et al. [9] lyophilised nerve tissue prior to weighing and extraction. Allowing for our use of wet weight, sugar concentrations are similar in the two studies. In none of these studies, including our own, has it been possible to examine the relationship between blood and nerve glucose concentrations.

Decreased myoinositol concentrations have been observed in the sciatic nerves from streptozotocin-diabetic rats $[3,6,16,17]$, although normal levels in spinal cord and sciatic nerve have also been reported [1]. Mayhew et al. [8] found a significant reduction in myoinositol concentration in post-mortem biopsies from diabetic patients, as did Brown et al. [18], in sural nerve biopsy in 3 diabetic patients. In contrast, we did not observe a significant difference in nerve myoinositol concentration between diabetic and non-diabetic patients.

Previous studies $[8,9]$ have examined nerve fascicles after removal of perineurium and endoneurium compared with our use of whole nerve. While glucose, sorbitol and fructose levels of the respective components of whole nerve are unknown, myoinositol concentrations of fascicles are higher than of whole nerve and may contribute to our failure to obtain significant differences.

While the possibility of altered nerve metabolism in the context of limb ischaemia or infection needs to be considered, biopsies were taken proximal to the amputation site and all patients subsequently showed satisfactory post-operative healing.

With the current interest in drugs that inhibit aldose reductase [19], it is clearly important to have in- 
formation on nerve glucose, sorbitol, fructose and myoinositol concentrations in diabetic patients. The current study has obvious advantages over tissue obtained at post-mortem, although other factors such as glucose control peri-operatively, anaesthetic agents and analgesics may influence results. Further studies will be necessary to clarify these reservations.

\section{References}

1. Ward JD, Baker RWP, Davis BH (1972) Effect of blood sugar control on the accumulation of sorbitol and fructose in nervous tissue. Diabetes 21: 1173-1178

2. Gabbay KH (1975) Hyperglycaemia, polyol metabolism, and complications of diabetes mellitus. Ann Rev Med 26: 521-536

3. Palmano KP, Whiting PH, Hawthorne JN (1977) Free and lipid myo-inositol in tissues from rats with acute and less severe streptozotocin-induced diabetes. Biochem J 167: 229-235

4. Clements RS Jr (1979) Diabetic neuropathy - New concepts of its etiology. Diabetes 28: 604-611

5. Brownlee M, Cerami A (1981) The biochemistry of the complications of diabetes mellitus. Ann Rev Biochem 50: 385-432

6. Gillon KRW, Hawthorne JN, Tomlinson DR (1983) Myo-inositol and sorbitol metabolism in relation to peripheral nerve function in experimental diabetes in the rat: the effect of aldose reductase inhibition. Diabetologia 25:365 -371

7. Gillon KRW, Hawthorne JN (1983) Sorbitol, inositol and nerve conduction in diabetes. Life Sci 32: 1943-1947

8. Mayhew JA, Gillon KRW, Hawthorne JN (1983) Free and lipid inositol, sorbitol and sugars in sciatic nerve obtained post-mortem from diabetic patients and control subjects. Diabetologia 24: $13-15$

9. Dyck PJ, Sherman WR, Hallcher LM, Service FJ, O'Brien PC, Grina LA, Palumbo PJ, Swanson CJ (1980) Human diabetic endoneural sorbitol, fructose and myo-inositol related to sural nerve morphometry. Ann Neurol 8: 590-596

10. Tomlinson DR, Moriarty RJ, Mayer H (1984) Prevention and reversal of defective axonal transport and motor nerve conduction velocity in rats with experimental diabetes by treatment with the aldose reductase inhibitor Sorbinil. Diabetes 33: 470-476
11. Stribling D, Mirrlees DJ, Harrison HE, Earl DCN (1985) Properties of ICI 128436, a novel aldose reductase inhibitor, and its effects on diabetic complications in the rat. Metabolism 34: 336-344

12. McCallum KNC, Sharma AK, Blanchard DS, Stribling D, Mirrlees DJ, Doguid M, Thomas PK (1986) The effect of continuous insulin infusion therapy on morphological and biochemical abnormalities of peripheral nerves in experimental diabetes. J Neurol Sci 74: 55-67

13. Somogyi M (1945) Determination of blood sugar. J Biol Chem 160: 69-73

14. De Neef J (1969) Quantitative determination of mixtures of monosaccharides, disaccharides and alditols as their trimethylsilyl ether derivatives by gas-liquid chromatography. Clin Chim Acta 26: 485-490

15. Cohen L, Holliday M (1982) Statistics for social scientists. Harper and Row, London, pp 239-241

16. Greene DA, De Jesus PV, Winegrad AI (1975) Effects of insulin and dietary myoinositol on impaired peripheral motor nerve conduction velocity in acute streptozotocin diabetes. J Clin Invest 55: $1326-1336$

17. Clements RS Jr, Stockard CR (1980) Abnormal sciatic nerve myo-inositol metabolism in the streptozotocin-diabetic rat. Diabetes 29: 227-235

18. Brown MJ, Iwamori M, Kishimoto Y, Rapoport B, Moser HW, Asbury AK (1979) Nerve lipid abnormalities in human diabetic neuropathy: A correlative study. Ann Neurol 5: 245-252

19. Stribling D, Perkins CM (1986) Aldose reductase inhibitors. In: Nattrass M (ed) Recent advances in diabetes 2. Churchill Livingstone, Edinburgh, pp 169-176

Received: 13 October 1986

and in revised form: 18 May 1987

Dr. P.J. Hale

Diabetic Clinic

General Hospital

Steelhouse Lane

Birmingham $\mathrm{B} 46 \mathrm{NH}$

UK 